\title{
Zoneamento ecológico econômico como ferramenta para a gestáo territorial integrada e sustentável no Município do Rio de Janeiro
}

Vera Jane Ruffato-Ferreira. Universidade Federal do Rio de Janeiro, Rio de Janeiro, Brasil.

Leandro Beser. Universidade Estadual do Rio de Janeiro, Rio de Janeiro, Brasil.

Daniel de Berrêdo-Viana. Universidade Federal do Rio de Janeiro, Rio de Janeiro, Brasil.

Cynara França. Universidade Federal do Rio de Janeiro, Rio de Janeiro, Brasil. José Nascimento. Instituto Brasileiro de Geografia e Estatística (IBGE), Rio de Janeiro, Brasil.

Marcos Freitas. Universidade Federal do Rio de Janeiro, Rio de Janeiro, Brasil.

RESUMo | A paisagem e o contexto de inserção do meio urbano no ambiente natural são importantes fatores de visibilidade nacional e internacional da Cidade do Rio de Janeiro, destacando-se como um importante motivo de se pensar em um modelo de planejamento urbano focado na conservação ambiental e na sustentabilidade do município. O presente artigo apresenta uma proposta de implementação do Zoneamento Ecológico Econômico como ferramenta de planejamento e gestão para o município dentro de uma perspectiva integrada onde as diretrizes para uso e ocupação do solo sejam estabelecidas de forma participativa, abrangendo diversas dimensōes da sustentabilidade da cidade (ecológica, econômica e social).

PALAVRAS CHAVE | planejamento urbano, sustentabilidade urbana, planejamento territorial.

ABSTRACT | The relationship between natural elements and developed areas of the Rio de Janeiro landscape is the main reason for its national and international visibility, a major incentive for the creation of an urban planning models that focus on environmental preservation and sustainable development. The current article presents a proposal for implementing the Ecological-Economic Zoning as a tool for planning and managing the municipality through an integrated perspective. Guidelines for land use and occupation are defined in a participative manner, encompassing and integrating the ecological, economic and social dimensions of urban sustainable development.

KEYWORDs | urban planning, urban sustainability, territorial planning.

Recibido el 17 de mayo de 2016, aprobado el 1 de julio de 2016

E-mails: V.J. Ruffato-Ferreira, veraruffato@ivig.coppe.ufrj.br | L. Beser, leandrobeser@gmail.com | D. de Berredo, danberredo@ivig.coppe.ufrj.br |

C. França, cynara@ivig.coppe.ufrj.br | J. Nascimento, jose.sena@ibge.gov.br | M. Freitas, mfreitas@ppe.ufrj.br 


\section{Introdução}

O Zoneamento Ecológico Econômico (ZEE) nasceu com a pretensão de integrar aspectos naturais e sociais na gestão do território nacional, além dos econômicos já utilizados no planejamento tradicional (Ministério do Meio Ambiente [MмA], 2011). Neste contexto o ZEE rompeu com o paradigma de ferramenta autodirecionada para a classificação do território com base num determinismo natural, para incluir a vontade e a ação humanas como elementos compositores da ecologia do ambiente latu sensu (Marques \& Marques, 2007).

Esse instrumento tem sido utilizado na tentativa de ordenação do território brasileiro buscando harmonizar os interesses econômicos, sociais e ambientais. $\mathrm{O}$ ZEE difere dos zoneamentos clássicos, pois sua execução demanda de um grande esforço de integração de políticas públicas, ações de todas as esferas de governo, interesses econômicos e ambientais, além da articulação e debate com a sociedade civil, considerando suas perspectivas e opiniôes sobre a gestão e utilização do território. Em termos gerais o zEE pode ser considerado a ferramenta de zoneamento ambiental, focada na sustentabilidade.

O desenvolvimento da metodologia do Zoneamento Ecológico Econômico (zEE) foi influenciado pelos resultados da Conferência das Naçóes Unidas sobre Meio Ambiente Humano, ocorrida em 1972 em Estocolmo e reforçada posteriormente pela Conferência das Naçóes Unidas sobre o Meio Ambiente e o Desenvolvimento que ocorreu no Rio de Janeiro em 1992, conhecida como Eco 92 ou Rio 92 (MMA, 2011). A metodologia foi pensada para atender projetos de planejamento territorial nas escalas nacional e macrorregional (no caso da Amazônia Legal). Em seguida, foi proposta em diversas iniciativas de planejamento em outras escalas (estaduais e/ ou regionais e locais). A experiência de utilização em áreas urbanas é extremamente recente, tendo sido iniciada na cidade de Goiânia.

O ZEE constitui-se assim, portanto, um instrumento que se propôe a ampliar a relação homem-natureza, fazendo a interseção entre políticas públicas e meios de produção, de forma que a biodiversidade passa a ser compreendida como base da sustentabilidade dos ecossistemas naturais, dos serviços ambientais, dos recursos florestais e pesqueiros, da agricultura e da nova indústria da biotecnologia (MMA, 2006b).

No âmbito desse mesmo contexto quando foi desenvolvido o ZEE, também se iniciou internacionalmente a incorporação da preocupação com a sustentabilidade ambiental e com a qualidade de vida nas cidades e discussão sobre a inserção do debate da sustentabilidade no âmbito do Planejamento Urbano, passando a ser chamado de Urbanismo Verde.

Segundo Scandurra (1995) a complexidade estrutural da inserção da questão ambiental no planejamento urbano é caracterizada pela irredutibilidade de seus fenômenos, irreversibilidade e não linearidade dos processos subjacentes. Tal situação remete à necessidade de uma visão global para o planejamento das cidades, preocupada com as inter-relaçóes entre os subsistemas urbanos (transporte, saneamento, infraestrutura, energia, segurança, educação, etc.), naturais e sociais. 
Um aspecto importante para uma política global de renascimento das cidades seria a descentralização do poder, com a consolidação da participação social (Healey, 1992; Scandurra 1995). Em uma cidade sustentável, a tomada de decisão deve ser partilhada com o governo, os órgãos da administração pública, os cidadãos e demais interessados.

Assim, numa perspectiva ideal, a cidade passa a ser vista como ponto de encontro entre ecologia e urbanística e, desse modo, a administração municipal deve abandonar as suas atividades reducionistas e determinísticas e criar um pool de especialistas interdisciplinares com a competência necessária para enfrentar as condições de sobrevivência do sistema vivo urbano. Nessa concepção, é necessário conjugar interesses públicos com privados, interesses coletivos com individuais, sem hierarquia ou prioridade. O intuito é minimizar e, num plano utópico, neutralizar, os conflitos relacionados aos diversos usos do território e aos diversos modos de conceber a organização da cidade por parte dos diferentes atores sociais, em prol de um bem maior comum.

Para tal, deve-se tomar como base a concretude do espaço, representado como o lócus das relaçóes sociais e onde acontecem os conflitos, Santos (1996, p. 51) afirma que "o espaço é formado por um conjunto indissociável, solidário e também contraditório, de sistemas de objetos e sistemas de açôes, não consideradas isoladamente, mas como o quadro único no qual a história se dá”. De um lado, os sistemas de objetos condicionam a forma como se dão as açóes e, de outro lado, o sistema de açóes leva à criaçáo de objetos novos ou se realiza sobre os preexistentes. Nesse processo, a historicidade é fundamental para o entendimento das contradiçóes e conflitos ambientais no espaço urbano (Beser de Deus, 2013).

Desta forma, entende-se que a questáo ambiental não pode ser apreendida em sua totalidade fora do contexto processual (social e histórico) da organização espacial (Galvão, 1992). Além disso, a abordagem geográfica do tema pode colaborar com a reflexão, principalmente no que diz respeito às escalas e às estratégias de intervenção no espaço, ao processo de tomada de decisão e às imposiçóes de atores institucionalizados (Pires do Rio \& Galvão, 1996).

Dentro da perspectiva em questão, assume-se a concepção adaptada de Acselrad (2004) que define conflitos ambientais como aqueles que envolvem grupos sociais com modos diferentes de apropriação, de uso e de significação do espaço. A origem desses conflitos se dá quando pelo menos um dos grupos tem a continuidade das formas sociais de apropriação do meio. Quando enfrenta as ameaças geradas por impactos indesejáveis - transmitidos pelo solo, pela água, pelo ar ou por sistemas vivos-, decorrentes das práticas de outros. Esses conflitos têm por arena unidades espaciais de poder ou territoriais, compartilhadas por um conjunto de atividades cujo "acordo simbiótico" é rompido em função de denúncia dos efeitos indesejáveis da atividade de um dos agentes sobre as condiçóes materiais e ambientais do exercício das práticas de outros agentes.

Como pode ser constatada, a noção de conflito ambiental vem sendo pensada sob uma perspectiva dinâmica que identifica as lutas sociais estabelecidas em torno de recursos naturais constituídos numa mesma base territorial (Borsoi, 2007; Oliveira, 2004). Com base nessa concepção, pode-se dizer que conflitos ambientais 
não são recentes. São séculos de disputas pela apropriação e uso dos recursos naturais. Há vários exemplos possíveis: têm-se os conflitos de uso do solo pela expulsão de pescadores tradicionais pelo crescimento da especulação imobiliária e crescimento urbano decorrente da localização de novos polos de emprego.

David Harvey, em artigo traduzido do original em inglês "The right to the city", menciona que vivemos num mundo onde os direitos de propriedade privada e as taxas de lucro se sobrepóem a todas as outras noçóes de direito. Nesse contexto, o presente artigo procura explorar outro tipo de direito humano, o direito à cidade:

A questáo de que tipo de cidade queremos não pode ser divorciada do tipo de laços sociais, relação com a natureza, estilos de vida, tecnologias e valores estéticos desejamos. O direito à cidade está muito longe da liberdade individual de acesso a recursos urbanos: é o direito de mudar a nós mesmos pela mudança da cidade. Além disso, é um direito comum antes de individual, já que essa transformação depende inevitavelmente do exercício de um poder coletivo de moldar o processo de urbanização. A liberdade de construir e reconstruir a cidade e a nós mesmos é, como procuro argumentar, um dos mais preciosos e negligenciados direitos humanos. (Harvey, 2012, p. 74).

Tendo como plano de fundo este arcabouço teórico-conceitual que as linhas do Planejamento Urbano se cruzam com os objetivos propostos pela metodologia do ZEE como um instrumento que se propóe a ampliar a relação homem-natureza, fazendo uma interseção crítica entre políticas públicas, meios de produção, biodiversidade e sociedade, que passa a ser compreendida como base da sustentabilidade dos ecossistemas naturais, dos serviços ambientais, dos recursos florestais e pesqueiros, da agricultura e da nova indústria da biotecnologia (MMA, 2006b). Dessa forma, a metodologia do ZEE tem o potencial de ser adaptada para a sua aplicação no contexto do planejamento urbano.

O objetivo deste trabalho é analisar a viabilidade da implementação do Zoneamento Ecológico Econômico no Município do Rio de Janeiro, visando uma melhor gestão do território aliada à gestão ambiental. Serão abordadas também as vantagens/desafios trazidos pelo ZEE ao município como instrumento de apoio ao planejamento territorial e ambiental visando à sustentabilidade, dado suas características ambientais peculiares, seu grande adensamento urbano, e os fatores de pressão que acarretam na vulnerabilidade ambiental.

Para a execução da análise proposta, foi realizado um exaustivo levantamento bibliográfico tanto sobre o ZEE no Brasil (seu histórico, metodologias, avaliações, problemas e soluçóes encontrados, entre outras questóes) quanto da atual situação do Município do Rio de Janeiro em diversos aspectos de seu planejamento urbano e conservação ambiental, entre outros.

\section{Arcabouço metodológico do ZEE}

Segundo o MMA (2006a), a elaboração do zEE é dividida em quatro etapas principais, a saber: planejamento, diagnóstico, prognóstico e subsídios à implementação, cada qual com suas subdivisóes. Em uma visão generalizada, o zEE parte de uma 
abordagem ampla de detecção de problemas e métodos a serem aplicados na busca de solução desses problemas. Do ponto de vista operacional, os resultados obtidos deverão ser considerados para a elaboração de estratégias e políticas, buscando encontrar os meios exatos para integrar variáveis ambientais, sociais e econômicas envolvidas nos projetos. Todas as etapas são conduzidas segundo os princípios norteadores apresentados no tabela 1.

Tabela I | Princípios Norteadores do ZeE

\begin{tabular}{|l|l|}
\hline $\begin{array}{c}\text { PRINCÍPIO } \\
\text { NORTEADOR }\end{array}$ & \multicolumn{1}{c|}{ DESCRIÇÃo } \\
\hline Participativo & $\begin{array}{l}\text { Os atores sociais devem intervir durante as diversas fases dos trabalhos, desde a concep- } \\
\text { çâo até a gestâo, com vistas à construçáo de seus interesses próprios e coletivos, para que } \\
\text { o ZEE seja autêntico, legítimo e realizável. }\end{array}$ \\
\hline Equitativo & $\begin{array}{l}\text { Igualdade de oportunidade de desenvolvimento para todos os grupos sociais e para as } \\
\text { diferentes regiôes. }\end{array}$ \\
\hline Sustentável & $\begin{array}{l}\text { O uso dos recursos naturais e do meio ambiente deve ser equilibrado, buscando a } \\
\text { satisfação das necessidades presentes sem comprometer os recursos para as próximas } \\
\text { geraçóes. }\end{array}$ \\
\hline Holístico & $\begin{array}{l}\text { Abordagem interdisciplinar para a integração de fatores e processos, considerando a } \\
\text { estrutura e a dinâmica ambiental e econômica, bem como os fatores histórico-evoluti- } \\
\text { vos do patrimônio biológico e natural. }\end{array}$ \\
\hline Sistêmico & $\begin{array}{l}\text { Visão sistêmica que propicie a análise de causa e efeito, permitindo estabelecer as rela- } \\
\text { çôes de interdependência entre os subsistemas físico-biótico e socioeconômico }\end{array}$ \\
\hline FONTE & MMA, 20 I I
\end{tabular}

$\mathrm{Na}$ etapa de planejamento são identificadas as demandas técnicas, financeiras, institucionais e sociais, além de mobilizados os recursos financeiros e humanos necessários à execuçáo do projeto. Geralmente os projetos de ZEE demandam de um diagnóstico socioeconômico e ambiental abrangente, o que requer uma grande diversidade de profissionais, estudiosos e pesquisadores de diversas áreas. $\mathrm{O}$ grande desafio, contudo, é a conciliação de todos estes profissionais a um ponto de vista e objetivo comuns, sem que nenhuma das subáreas fique renegada à segundo plano e, ao mesmo tempo, gerir e administrar as divergências (MMA, 2006a).

$\mathrm{Na}$ segunda etapa de diagnóstico é onde ocorre o levantamento dos dados e a elaboração de uma base de informaçóes. Nesta etapa são levantadas todas as características ambientais e socioeconômicas da região, além dos fatores jurídicos e institucionais que de alguma forma influenciem na dinâmica e planejamento local. Cabe ressaltar que o diagnóstico não consiste em um levantamento aleatório e exaustivo de dados, mas sim em um procedimento específico de correlação e síntese de informações viabilizada pela a utilização de modernas técnicas de geoprocessamento e interpretação de imagens de satélite. O objetivo central desta etapa é a caracterização da situação atual a fim de embasar a construção dos cenários e a formulação de propostas para a elucidação dos problemas encontrados nas etapas subsequentes (MMA, 2006a). 
A terceira etapa de prognóstico consiste exatamente na prospecção de cenários a partir da correlação das informaçóes levantadas com a situaçáo atual. Tendo, assim, o objetivo de simular possíveis situaçóes a fim de orientar o planejador e o gestor público na identificação de problemas e na escolha de possíveis alternativas e soluçóes mais adequadas ao desenvolvimento sustentável. Estes cenários devem ser construídos considerando sempre a participação efetiva de todos os atores envolvidos no processo, e têm por objetivo: Identificar ameaças e oportunidades decorrentes das variaçóes de contextos; preparar o Programa para as possibilidades de atuação futura; ajudar na tomada de decisóes para a formulação de objetivos e estratégias institucionais alternativas; subsidiar a elaboração de planos voltados à implementação do ZEE; e, auxiliar a dar respostas às necessidades de novas informaçôes, pesquisas, proposição de açôes e articulaçóes político-institucionais para a execução do ZEE (MMA, 2006a)

A quarta e última etapa desse processo consiste em dar subsídio e auxiliar a implementação das propostas balizadas no zEE e o apoio à gestáo ambiental local. Uma das ferramentas, para tal, consiste na estruturação de um Sistema de Informação, com a finalidade de organizar e concentrar as informaçóes e ao mesmo tempo descentralizar o seu acesso contando com ampla divulgaçáo a todos os agentes envolvidos (MMA, 2006a).

O ZEE pode ser elaborado em diversas escalas geográficas (nacional, macrorregional, estadual ou regional e local), mencionadas pelo Decreto no 4.297/02 (que estabelece critérios mínimos para elaboração do zEE). Deve-se ressaltar que, para regulação do uso do território e aperfeiçoamento das políticas públicas, o zEE pode desempenhar diferentes funçóes intermediárias segundo a escala geográfica em que o zoneamento é aplicado. De forma aplicada, Becker e Egler (1997) citam que:

Assim, à escala global, o zoneamento tende a conceber toda a Amazônia Sulamericana como uma imensa zona a ser preservada. Na escala nacional, que é a de interesses gerais, trata-se da regulação do uso do território nacional que é estratégica; a finalidade do zeE nesta escala é otimizar o uso da grande reserva de terras e recursos do país, reconhecendo e direcionando as grandes tendências que a estruturam. É complementada pela escala macrorregional, em que o zEE deveria proporcionar a visão de conjunto da regiấo, setorizada em macrozonas de intervençãó ${ }^{1}$; num diagnóstico ambiental previsto para ser elaborado pelo IBGE, na escala de 1:1.000.000. É diversa a finalidade à escala regional. $\mathrm{O}$ zEE deve identificar áreas prioritárias a serem detalhadas (1:250.000), e segundo o interesse dos estados ${ }^{2}$. Trata-se de uma escala intermediária para regular o uso do solo, segundo o que é conhecido como 'land use planning', mais eficiente à escala de 1:100.000. (Becker \& Egler, 1997).

Especificamente para o Zoneamento Local, no inciso III do Decreto supracitado, as escalas locais de 1:100.000 e maiores são destinadas para indicativos operacionais de gestão e ordenamento territorial, tais como, planos diretores municipais, planos de gestão ambiental e territorial locais, usos da Áreas de Preservação Permanente.

1 Programa de zeE da Amazônia Legal estabelecido em 1991.

2 Programa de zee da Amazônia Legal estabelecido em 1991. 
Dessa forma, o instrumento já possui a premissa legal da possibilidade de aplicação em espaços urbanos.

\section{Aspectos ambientais no Município do Rio de Janeiro}

O município do Rio de Janeiro possuía, originalmente, todo o seu território inserido no Bioma Mata Atlântica, que é considerado Patrimônio Nacional pela Constituição Federal. A Mata Atlântica é, também, considerada internacionalmente como um dos Biomas com maiores valores de diversidade biológica do planeta, também conhecido como Hotspot de Biodiversidade (Conservation International, 2011).

Mesmo com o grande adensamento populacional e a segunda maior população urbana do país, o Rio de Janeiro é o $67^{\circ}$ município com uma maior proporção relativa de área preservada de Mata Atlântica em Função da área total original (32\% da área original preservada) do total dos 623 municípios analisados. O município do Rio de Janeiro se destaca por ser o com maior área preservada comparando-o com outras capitais analisadas como São Paulo e Vitória além de se colocar melhor posicionado do que muitos municípios pequenos (Ferreira, 2011). Contudo, grande parte destas áreas preservadas se encontra dentro das Unidades de Conservação que perfazem atualmente um total de 53 dentre as de subscrição federal, estadual e municipal (Secretaria Municipal de Meio Ambiente [sMAC], 2008).

Apesar de possuir, relativamente, boa parte de suas áreas naturais preservadas, a conservação das espécies que compóes estes ecossistemas encontram-se com um elevado nível de ameaça. Segundo a lista de espécies ameaçadas de extinção no Município do Rio d e Janeiro (sMAC, 2000). Existe um total de 50 espécies já extintas no município do Rio de Janeiro, sendo destas 27 da flora e 23 da fauna, isso sem considerar possíveis espécies perdidas, antes mesmo de serem descritas. Quanto às ameaçadas de extinção, enquadradas nas categorias em perigo e vulnerável, segundo parâmetros da International Union for Conservation of Nature (IUCN), foram diagnosticadas 345 espécies, sendo 274 da flora e 170 da fauna e mais 46 espécies enquadradas como criticamente em perigo (CR), sendo 35 da flora e 14 da fauna, totalizando 444 espécies ameaçadas de extinção no município.

Outra característica ambiental degradante na cidade é a poluição dos recursos hídricos. De acordo com a Fundação Estadual de Engenharia Do Meio Ambiente (feEma, 2006), a cidade do Rio de Janeiro apresenta três Macro-Bacias Hidrográfica: a Bacia da Baía de Guanabara, a Bacia das Lagoas Oceânicas e a Bacia da Baía de Sepetiba. Todas as três Bacias possuem problemas críticos da poluição de suas águas principalmente pelo despejo de esgoto sanitário "in natura” e também com a contaminação por substâncias tóxicas e metais pesados provenientes do despejo industrial histórico e irregular (FEEMA, 2006; 2007).

A despeito dos problemas ambientais característicos de áreas características do grande adensamento urbano, a conservação de uma grande área florestada na cidade do Rio de Janeiro foi proporcionada por suas características geográficas. A cidade do Rio de Janeiro encontra-se inserida em um vale delimitado por três maciços, Tijuca, Pedra Branca e Gericinó, mais a planície costeira. Assim, parte significativa das áreas conservadas está localizada em áreas íngremes e de difícil ocupação. Tal 
fato, em conjunto com sua localização costeira, levou à formação de uma cidade praticamente inserida dentro de áreas naturais.

O contraste marcante do sítio da cidade do rio de Janeiro, formado entre o urbano e o natural, criou paisagens singulares. Essa peculiaridade fez com que a cidade do Rio de Janeiro seja, até hoje, considerada uma das mais belas do mundo, o que levou, inclusive, ao mMa e ao Instituto do Patrimônio Histórico e Artístico Nacional (IPHAN)), prepararem um dossiê para a candidatura do Rio a Patrimônio Mundial, na categoria Paisagem Cultural, na unEsco através dos seus assessores, ICOMOs (International Council on Monuments and Sites) e IUCN (International Union for Conservation of Nature) (Batista, 2009).

Apesar da importância das áreas naturais para o município, não só por seus serviços ambientais, mas também por fazer parte da imagem cultural da cidade, um recente estudo de indicadores e mapeamentos de uso e ocupaçáo do solo realizado pelo Instituto Municipal de Urbanismo Pereira Passos (IPP) em parceria com a SMAC apresentou um quadro crítico dessa situação. A partir do diagnóstico produzido, dois fatores que influenciam essa pressão sobre as áreas naturais foram identificados: 1 . O crescimento urbano e econômico da cidade em direção, principalmente na Zona Oeste (aps 4 e 5); 2 . O crescimento de áreas favelizadas e da ocupação ilegal em áreas de preservação (tanto pela população pobre com a formação de favelas, quanto pela população rica, em busca de melhor qualidade de vida que foge da conturbação urbana e busca maior contato com a natureza). Esse último especialmente preocupante, pois além da perda de áreas naturais acarreta também à cidade sérios problemas relacionados à vulnerabilidade ambiental (sMAC, 2005). Nas Figuras 1 e 2, pode-se observar o contrate da redução das áreas naturais que coincidem com a expansão das áreas urbanas entre os anos de 1985 e 2001.

\section{FIGURA I | Crescimento da urbanização - 1984-2001}

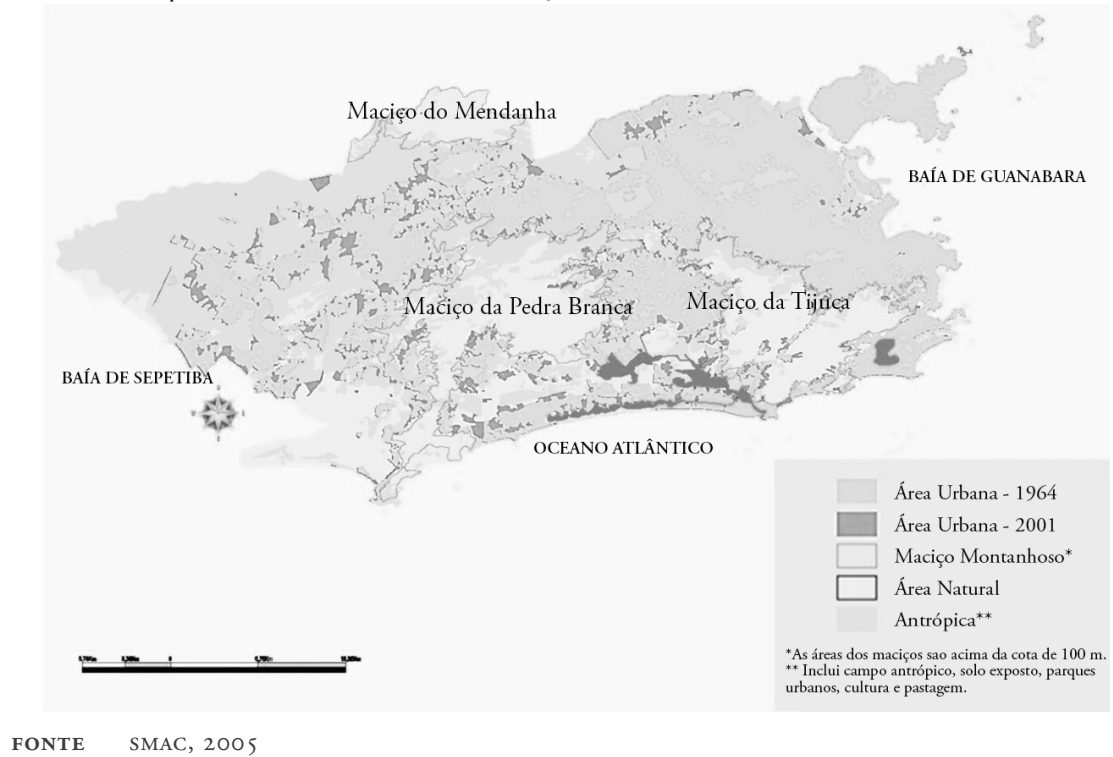


FIGURA 2 | Variação da cobertura vegetal nativa - 1984-2001

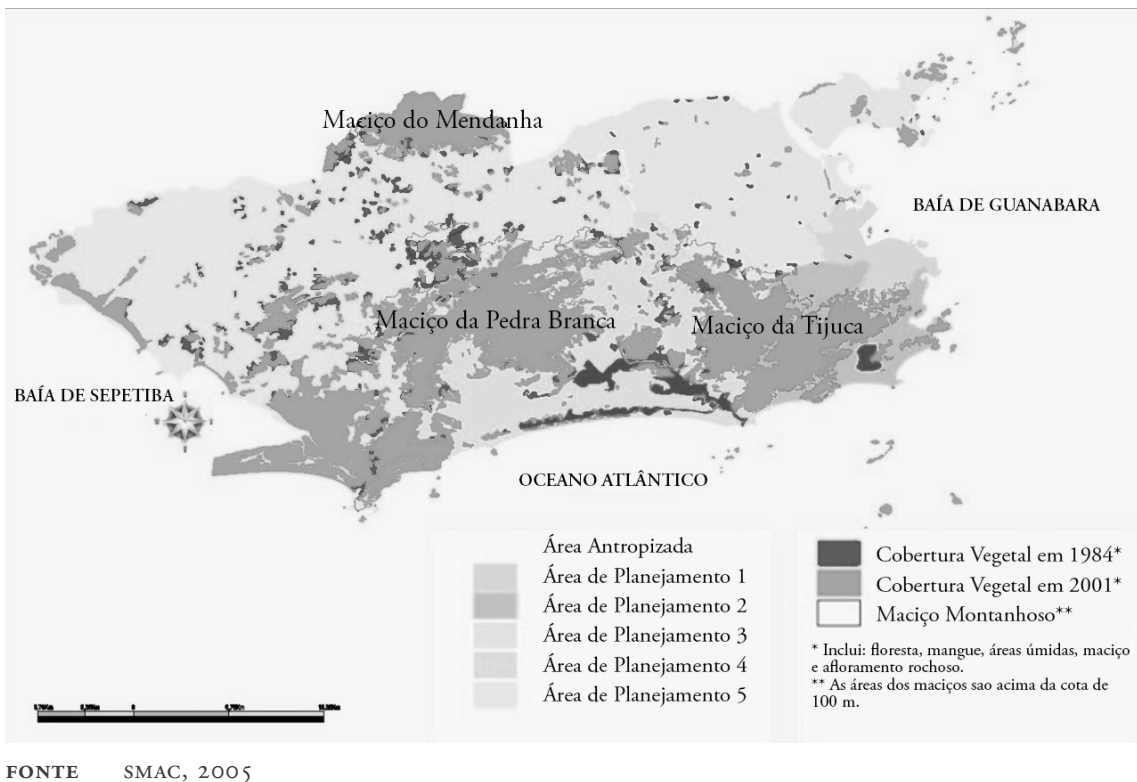

A necessidade de se reduzir os conflitos entre o crescimento da cidade e a conservação ambiental, garantindo a manutenção dos serviços ambientais das florestas, possui um ganho econômico, social e em qualidade de vida, indiscutíveis. A estabilização e preservação das encostas reduzem os riscos e a vulnerabilidade ambiental, reduzindo também os gastos do poder público e as perdas sociais e até mesmo de vidas humanas em desastres de desbarrancamentos. A manutenção de bons índices de qualidade do ar reduz, entre outros problemas, o número de pessoas com doenças respiratórias e consequentemente os gastos de saúde pública com o tratamento dessas pessoas, além de melhorar a qualidade de vida da população.

Assim sendo, o fato de a cidade do Rio de Janeiro ainda possuir uma relativa área verde preservada não deve servir de pressuposto para uma exploração desordenada das mesmas. Hoje, já é consenso que a visão de Meio Ambiente restrita a Unidades de Conservação está ultrapassada. A compreensão do ambiente urbano integrado ao ambiente natural está cada vez mais consolidada. Águas, microclima urbano, qualidade do ar, entre outros, são aspectos ambientais que permeiam a cidade, não estando restritos às áreas verdes, e o objetivo global passa a ser a de garantir a qualidade ambiental da cidade como um todo, justificando a necessidade de se explorar ferramentas de planejamento territorial que integrem as questóes ambientais, como é o caso do zeE. 


\section{Panorama econômico e social no Município do Rio de Janeiro}

Os dados referentes à distribuição espacial e de uso e ocupação do solo da cidade do Rio de Janeiro indicam que há na cidade áreas mais ricas e afluentes, em oposição a outras mais pobres e sem infraestrutura. O município do Rio de Janeiro apresentase dividido e está organizado de maneira hierárquica influenciada principalmente pela distância das estruturas produtivas e do mercado de trabalho. Essa estruturação social urbana segregada da cidade pode ser explicada tanto pelos acontecimentos históricos, quanto pela ação do mercado imobiliário, que funciona como mecanismo seletivo ao acesso a moradia nas diversas áreas da cidade. Este cenário também é agravado pela falta da existência de um planejamento concreto de desenvolvimento e uma política de uso e ocupação do solo da cidade. A diferença na distribuição da estrutura urbana e da oferta de serviços públicos básicos (saúde, educação, saneamento, transporte, etc.), acesso ao lazer e a cultura e ofertas de empregos que também seguem esta segregação e influenciam diretamente na qualidade de vida da população.

O trabalho publicado pelo Instituto Pereira Passos (Ipp, 2001) acerca da estrutura organizacional da sociedade, segregação de moradia e desigualdade na cidade metrópole Rio de Janeiro, nos mostra bem este quadro de segregação. Esse trabalho utilizou como base classificação proposta elaborada para a metrópole fluminense com as diferenças no perfil ocupacional da população, dividindo-a em 8 categorias (ocupaçóes agrícolas; elite dirigente; pequena burguesia; profissionais de nível superior; trabalhadores não-manuais de nível médio; trabalhadores do comércio e serviços; trabalhadores manuais da indústria e serviços; e trabalhadores da sobrevivência) que foram criadas a partir da combinação de variáveis como ocupação, posição na ocupação, setor de atividades, renda e escolaridade. A partir de um recorte intrarregional, é possível verificar a distribuição dos tipos socioespaciais no território do município mapeada na figura 3.

Como entendimento da construçáo histórica do espaço urbano do Rio de Janeiro, pode-se perceber que a distribuição geográfica social apresentada é bem definida na cidade sendo formada por um núcleo, onde está concentrada a maior parte das estruturas produtivas e do mercado de trabalho e, consequentemente, dos seguimentos superiores da estrutura social. O núcleo trata-se da regiáo litorânea (Zona Sul, Barra e Recreio), que se destaca por ser ocupada por essas camadas superiores. Nessa regiáo pode-se desfrutar de uma melhor qualidade de vida, visto que nela se concentram boa parte dos serviços prestados, equipamentos urbanos/culturais e sedes de diversas empresas, além de também contarem com a proximidade do mar e com suas inúmeras áreas verdes para a amenização natural do clima e da poluição atmosférica comum em todas as grandes cidades.

Ainda de acordo com o documento produzido (IPP, 2001), duas situaçôes, contudo, rompem com esta lógica socioterritorial. A primeira é a presença de espaços médio-superiores e médios na Zona Oeste que apresenta tendências à diversificação social de parte da periferia. A segunda situação está relacionada com a presença das favelas (espaços do tipo popular e operário) nas áreas superiores: 
"traço característico do modelo de segregação urbana ${ }^{3}$ vigente na Cidade do Rio de Janeiro, que combina distância social com proximidade física” (IPP, 2001, p. 6).

FIgura 3 | Estrutura social do Rio de Janeiro 1991. (Observatório de Políticas Urbanas e Gestão Municipal)

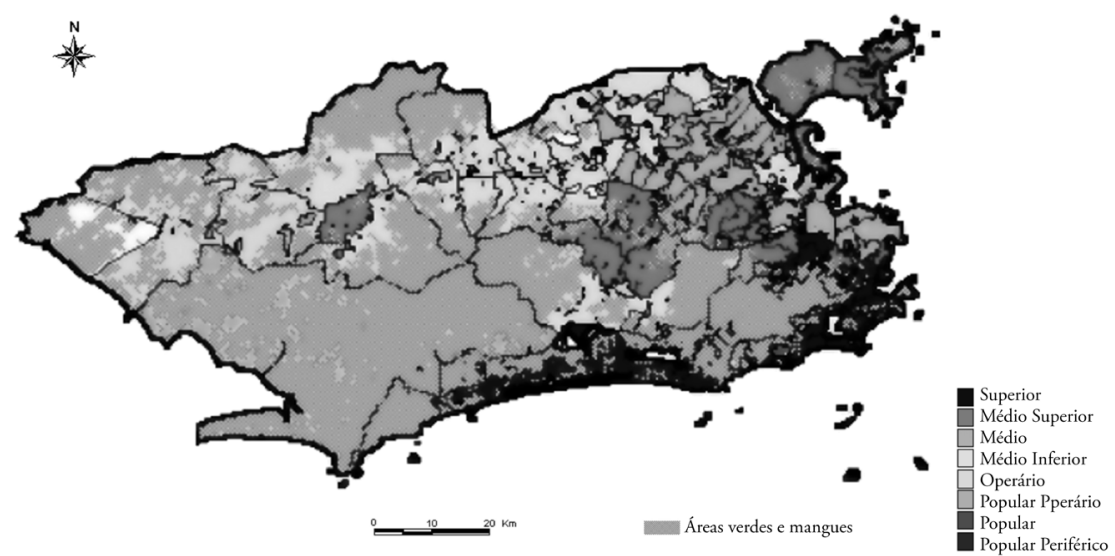

FONTE IPPUR/UFRJ - FASE, 2000 APUD IPP, $200 \mathrm{I}$

Estima-se que em 2010 a população residente nessas áreas correspondia à $23 \%$ do total da população da cidade (1.443 mil habitantes) (IPP, 2012). Essas áreas estão espalhadas por todo o território urbano da cidade (tabela 2). Em termos absolutos a AP3 (Zona Norte) é a que concentra a maior população vivendo em favelas (654.755 habitantes). Em termos relativos, a API (Centro), é a região com a maior proporção de pessoas vivendo em favelas em relação a população total da região (35\%) (IPP, 2012). As favelas possuem inúmeros problemas sociais que espelham a desigualdade presente na cidade, sendo também a parte do espaço urbano com maior carência de infraestrutura (saneamento, espaços públicos, áreas verdes, urbanização etc.) e de ordenamento territorial. Trata-se de um espaço de segregação social, onde se concentra a parcela mais pauperizada da população. Essa é a parte do território representa também um desafio de planejamento e ordenamento territorial visando à melhoria da qualidade de vida da população.

3 Conhecida também como segregação socioespacial. Relacionada aos processos de periferização ou marginalização de pessoas ou grupos sociais por fatores (de econômicos a culturais) no espaço urbano. Souza (2000) cita que a favelização e a periferização são os traços mais característicos da pobreza urbana atualmente. Nessas áreas, há uma série de problemas, sobretudo aqueles relacionados à ausência de infraestrutura. Contudo, para o referido autor, o “(...) traço mais impressionante da favelização, da década passada pra cá, fica por conta (...) da territorialização de favelas por parte do tráfico de drogas" (Souza, 2000, p 193). Assim, esse quadro mostra bem a fragmentação do tecido sócio-político-espacial da cidade do Rio de Janeiro. 
TABela 2 População de favelas por Áreas de Planejamento Município do Rio de Janeiro - 2010

\begin{tabular}{|l|c|c|c|}
\hline \multicolumn{1}{|c|}{$\begin{array}{c}\text { ÁREA DE } \\
\text { PLANEJAMENTO }\end{array}$} & CIDADE (A) & FAVELA (B) & (B) / (A) \\
\hline Total & 6.320 .446 & 1.443 .773 & $23 \%$ \\
\hline AP1 - Central & 297.976 & 103.296 & $35 \%$ \\
\hline AP2 - Zona Sul & 1.009 .170 & 174.149 & $17 \%$ \\
\hline AP3 - Zona Norte & 2.399 .159 & 654.755 & $27 \%$ \\
\hline AP4 - Barra/Jacarepaguá & 909.368 & 236.834 & $26 \%$ \\
\hline AP5 - Zona Oeste & 1.704 .773 & 274.739 & $16 \%$ \\
\hline
\end{tabular}

FONTE IPP, 2012

O sítio urbano do Rio de Janeiro sofreu com um processo histórico de exploração de suas áreas naturais e adensamento populacional que culminou em diversos problemas de vulnerabilidade ambiental, que são, em sua maioria, consequência do crescimento desordenado em áreas de risco. Dentre os maiores problemas enfrentados podem ser citados os alagamentos, inundaçóes e deslizamentos de encostas. Diante da análise realizada das características geográficas da cidade do Rio de Janeiro, podese compreender um pouco melhor porque os riscos ambientais são táo acentuados.

Segundo Coelho Netto (2005) dois fenômenos de naturezas e interesses socioeconômicos distintos contribuem para o aumento da ocupação em áreas de encostas e proximidades de leitos de rios aumentando o risco e a vulnerabilidade ambiental. O primeiro deles trata-se do processo histórico de ocupação irregular e construção de favelas que está associado ao empobrecimento da população aliado a busca de moradias próximas aos locais com oferta de trabalho remunerado. Esse processo iniciado nas primeiras décadas do século $\mathrm{xx}$ intensifica-se cada vez mais, inclusive sobre as áreas de alto risco como já citado (encostas íngremes e instáveis e leitos de rios nas baixadas fluviais). O segundo trata-se de um movimento oriundo da classe mais privilegiada da sociedade que na expectativa de melhor qualidade de vida no ambiente montanhoso florestal e a fuga da violência urbana tem forçado o avanço de construçóes formais sobre as encostas, apesar das restriçóes impostas pelas legislaçóes ambiental e urbana. Sendo assim, essa parcela da população em conjunto com as empreiteiras da construção civil e empresas imobiliárias, pressionam o poder público por uma revisão urgente na legislação que restringe a ocupação dessas encostas. É nessas regióes também que estão localizadas grande parte dos remanescentes florestais da cidade, como evidenciado no item anterior. Desta forma, se o poder público se render a esta pressão e afrouxar esta regulamentação permitindo a ocupação dessas áreas, além de agravar os riscos e os problemas com a vulnerabilidade ambiental da população estará também favorecendo a redução das áreas naturais ainda existentes na cidade.

De acordo com o Estatuto da Cidade (Lei Federal no 10.257, de 10 de julho de 2001), instrumento legal que trata das questóes relacionadas ao planejamento e gestão urbana e territorial a nível municipal, é definido que: "a ordenação e controle do uso do solo deve garantir não só os interesses econômicos, mas também as 
necessidades coletivas, a instalação de infraestrutura urbana, o controle da poluição, da degradação ambiental e da deterioração das áreas urbanas, conservação do meio ambiente natural e do patrimônio histórico, artístico, cultural, paisagístico e arqueológico e garantir o desenvolvimento sustentável da cidade” (Brasil, 2001).

Neste contexto o Novo Plano Diretor da Cidade do Rio de Janeiro (Lei Complementar $n^{\circ} 111$, de $1^{\circ}$ de fevereiro de 2011), por meio das metas e diretrizes de crescimento propostas para a cidade. O Plano enfatiza a necessidade de um "desenvolvimento" sustentável e equitativo para a cidade, onde a ocupação urbana deve dar-se em equilíbrio com o meio natural e a conservação ambiental, contudo não define os instrumentos que deverão ser utilizados para alcançar esses objetivos (Rio de Janeiro, 2011). A síntese das diretrizes gerais do Novo Plano Diretor, incluindo seu objetivo central, para o qual todas as diretrizes convergem, está esquematizada na Figura 4.

Figura 4 Diretrizes Gerais do Uso e Ocupação do Solo no Município do Rio de Janeiro Previstos no Novo Plano Diretor, Lei Complementar $n^{\circ} 111$, de $1^{\circ}$ de fevereiro de 2011

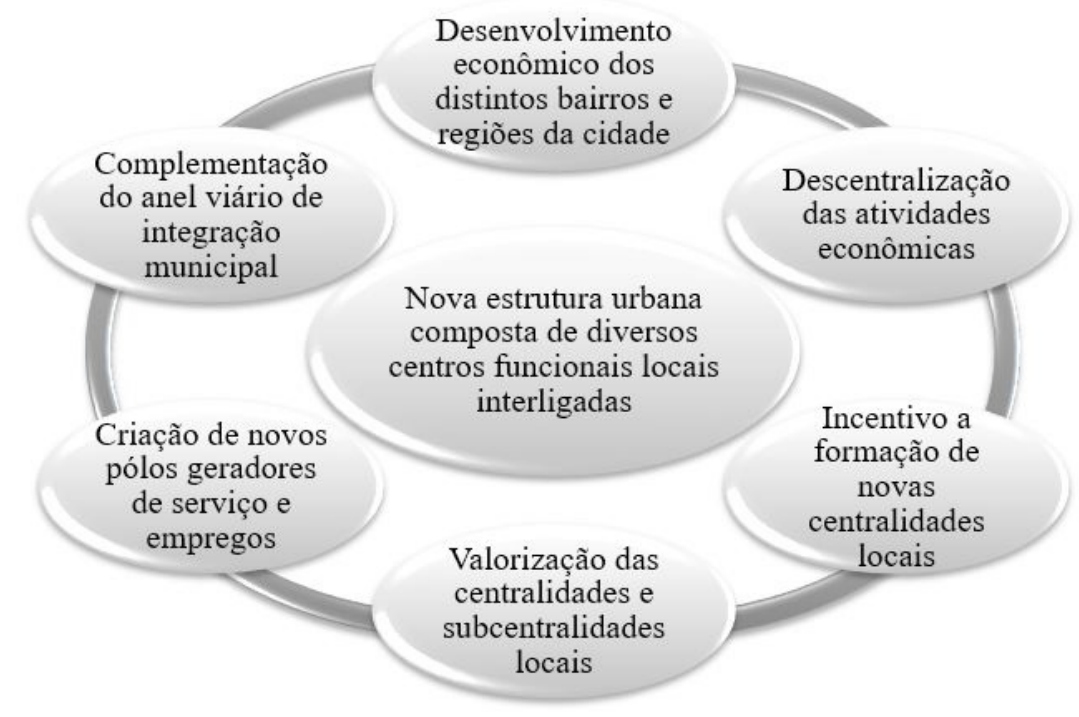

FONTE ELABORAÇÃo PRÓPRIA

\section{O ZEE como alternativa para o planejamento e ordenamento territorial Municipal}

Conforme já explicitado, o zEE consiste em um conjunto de técnicas estruturadas que visa romper o paradigma de consideração de determinismo natural para a classificação territorial, incluindo neste planejamento as vontades, açóes e interaçóes humanas, além da ecologia e do ambiente. Ele busca a otimização do uso de recursos 
e a expansão urbana com a redução da perda de áreas naturais, diversidade biótica e seus serviços ambientais, além da integração de todos esses fatores com as perspectivas e necessidades sociais. Cabe ressaltar que o modelo apresentado se trata de uma alternativa viável, existente e já utilizada em outras realidades. A metodologia geral para o zeE é determinada pelo Ministério do Meio Ambiente no contexto do Programa zee Brasil, contudo a mesma pode sofrer adaptaçóes visando melhor atender as características e necessidades da regiáo, visto que não existe um modelo único que possa atender as inúmeras configuraçôes socioambientais existentes no Brasil e em outras localidades no mundo.

Segundo Benatti (2003), o zEE é um instrumento apto a promover a sustentabilidade e busca proporcionar a melhoria na qualidade de vida, o desenvolvimento socioeconômico equilibrado das regióes, a gestão responsável dos recursos naturais, a proteção do meio ambiente e a participação da população durante todo o processo de planejamento e elaboração do instrumento. Além de ferramenta de planejamento, o zEE, também é um instrumento de gestão sustentável dado que ele prevê o gerenciamento a utilização dos recursos naturais de acordo com a capacidade de suporte do meio ambiente, visando protegê-lo para a utilizaçáo pelas geraçóes futuras (Attanasio, 2005).

O ZEE, ao funcionar como um sistema de informaçôes e de avaliação de alternativas com base em cenários futuros torna-se um instrumento em potencial para o auxílio à formulação de novos planos, sistemas de planejamento e também como base de articulação às açóes públicas e privadas que participam da estruturação do território levando em consideração as necessidades de proteção, recuperação e desenvolvimento com conservação.

Nesse contexto, o Zoneamento Ecológico Econômico constitui-se em uma importante ferramenta capaz de auxiliar no planejamento e gestão do município do Rio de Janeiro, visto que os seus objetivos e suas diretrizes condizem com as necessidades da cidade e as definiçóes previstas no Estatuto das Cidades e no Novo Plano Diretor do Município.

O ZEE, ao considerar as características da população, as vocaçóes e potencialidades dos bairros e regióes da cidade, a fim de melhor planejar o território, pode auxiliar nos ajustes das disparidades existentes entre os bairros quanto aos aspectos ambientais, econômicos, sociais e infraestruturais, de forma a promover uma maior equidade socioespacial para a cidade. Kikuchi (2007) ressalta que a maior parte das políticas públicas do Brasil não abrange a sociedade e nem atentam para suas influências ou consequências para a ocupação do território. As políticas voltadas para saúde e educaçáo, por exemplo, são elaboradas considerando diretrizes gerais voltadas para todo o país, sem considerar que as mesmas são diretamente influenciadas por demandas geradas pela ocupação territorial, seja ela planejada ou não e não pode ser generalizada em um país tão vasto e com particularidades locais e desigualdades tão acentuadas como o Brasil. Portanto, o zEE também pode subsidiar o planejamento das atividades mais propícias a serem instaladas em cada região.

Em vista disso, o ZEE viabilizaria o planejamento necessário para serem estruturadas as condiçôes para a implementação das demais diretrizes previstas no Plano Diretor: desenvolvimento econômico dos distintos bairros e regióes da cidade; 
descentralização das atividades econômicas e criação de novos polos geradores de serviço e empregos; e complementação do anel viário de integração municipal e também com a região metropolitana.

Outros benefícios que seriam atingidos com o atendimento dessas diretrizes seriam: a promoção e revitalizaçáo de todos os bairros e localidades da cidade, controle do adensamento urbano, otimização dos custos com infraestrutura, comunicação e abastecimento, além de desobstruir o trânsito da cidade, através da redução da necessidade de deslocamento da população, favorecendo, assim, a mobilidade urbana.

O zEE também é um instrumento com a finalidade de identificar as potencialidades e limitaçôes ecológicas, econômicas e sociais, além de considerar os impactos diretos e indiretos à sociedade e de possíveis problemas ambientais gerados pelo crescimento e expansão urbana. Com isso, esta ferramenta, se bem empregada, permite também que seja alcançada a sustentabilidade ambiental da cidade. Que, para tal, precisa-se também que haja uma organização do território focando a prevenção contra problemas ambientais causados pela ocupaçáo desordenada da cidade (Paula $\&$ Sales, 2007).

Em tese, a elaboração do ZEE municipal contribuiria tanto para a formulação de um planejamento integrado, colaborando com o debate e a articulação entre os diversos órgãos da administração pública, assim como garantiria a formulação de um planejamento de longo prazo, auxiliado pela previsão de cenários, facilitando a continuidade da gestáo ambiental e social mesmo com transiçôes de governo. As políticas ambientais de governo, propostas e eleitas democraticamente, devem ser respeitadas, contudo, devem ser condizentes com o planejamento de longo prazo, elaborado a partir de um pacto nacional/social, como a política de conservaçáo ambiental. Estas, por sua vez, precisam efetivamente ser tratadas como política de Estado, assim, como seus instrumentos, a exemplo do ZEE.

A ausência de continuidade administrativa comum nos municípios, visto que os problemas ambientais são em sua maioria de longo prazo, exige uma negociação lenta e um planejamento por etapas, os mesmos acabam sendo deixados sempre para o governo posterior.

Os autores Steinberg e Romero (2000) acreditam que a sustentabilidade auxilia na conciliaçáo de conflitos relativos à ocupação territorial uma vez que a regulação do território passa a ser abordada segundo três princípios básicos: eficácia, valorização da diferença e descentralização. Concluindo, eles consideram também que a ferramenta zEE trata-se de um instrumento de gestão territorial que auxilia a garantir a sustentabilidade tanto por seu caráter técnico, por classificar o território segundo suas potencialidades e vulnerabilidades e prover informaçóes integradas em uma base geográfica, quanto pelo político, por permitir a integração de políticas públicas além de ser um instrumento de negociação entre as esferas do governo, setor privado e sociedade civil.

A elaboração de cenários é outra das características existentes no zEE que auxilia neste sentido. Com o apoio de modelos de previsão e cenários, podemos diagnosticar a situação atual do território, elaborar e propor o debate e a troca de opinióes entre governantes, empreendedores e a sociedade, estabelecendo relaçóes sobre os 
rumos que os processos tomarão mediante a integração de todos esses fatores. Desta forma, é possível analisar criticamente tendências e criar caminhos alternativos a serem trilhados a fim de elaborar estratégias para que o resultado alcançado se coadune com as premissas de sustentabilidade (Marques \& Marques, 2007, op. cit.)

Acredita-se, portanto, que a perspectiva de se alcançar a sustentabilidade na cidade do Rio de Janeiro ajudará a satisfazer as necessidades da sociedade e atender as demandas de planejamento, gestão e reordenação territorial. Espera-se que a cidade se desenvolva com maior eficiência econômica e maximização dos benefícios gerados pelos recursos naturais a disposição de todos os cidadãos. Nesse sentido, a conservação e recuperação das áreas naturais são essenciais, restaurando suas funções ecossistêmicas e garantindo a manutenção dos serviços ambientais de forma mais abrangente possível. Deste modo, parcelas da população anteriormente excluídas, submetidas muitas vezes a situações de vulnerabilidade nos aspectos do risco natural e risco social, seriam beneficiadas efetivamente. Finalmente, teríamos possibilidades de manutenção e, quem sabe, incremento na qualidade de vida das geraçôes presente e futuras.

Apesar do grande potencial facilitador do planejamento e da gestão pública do ZEE, muitos gestores e formuladores dessas políticas ainda são descrentes desta ferramenta de ordenamento territorial. Segundo Kikuchi (2007), mesmo sem conhecer os preceitos e objetivos do ZEE a fundo, muitos formuladores de políticas públicas têm preconceito por acharem que este é um mecanismo que cerceia ou limita o desenvolvimento econômico. A falta de conhecimento e a herança da concepção de que a necessidade de crescimento econômico precede a todos os outros fatores os faz achar que o zEE possui um caráter restritivo.

Ainda de acordo com o autor, para que haja a quebra deste preconceito, deve-se haver um nivelamento de informaçóes entre os planejadores dos diversos órgáos de gestão para que o ZEE passe a ser compreendido como um instrumento de planejamento estratégico para o ordenamento territorial e não simplesmente como um instrumento de planejamento ambiental. Nesse contexto, deve ser entendido também que o zEE deve estar diretamente relacionado à elaboração das políticas públicas e ao ordenamento e a dinâmica territorial. Deve-se ressaltar que essas políticas não são subordinadas ao zEE (não há competição entre as políticas), mas sim imbricadas, no sentido de que uma pressupóe a outra, estando profundamente interligadas, conectadas, a fim de serem trabalhadas em conjunto, em prol do interesse coletivo.

\section{Conclusóes}

O Município do Rio de Janeiro possui características ambientais únicas que fazem parte inclusive da identidade nacional e internacional da cidade e, consequentemente, tornam importantíssimas as iniciativas de adoção de ferramentas de planejamento que englobem a conservação ambiental. Em contrapartida, nossas áreas naturais sofrem constantemente com as pressóes do crescimento urbano, da especulação imobiliária e das ocupações ilegais e desordenadas. 
Desta forma, o Zoneamento Ecológico Econômico se apresenta como uma importante ferramenta de planejamento e gestâo para ser implementada no Município do Rio de Janeiro a fim de se estabelecer na cidade um planejamento de uso e ocupação do solo integrado, participativo e que integre todas as dimensôes da sustentabilidade na cidade.

Com base nas discussóes entabuladas, podem-se estabelecer, em esquema conceitual, os benefícios esperados do zEE no processo de concretização de uma política pública integrada e também dos seus benefícios para a administração pública, a sociedade e o meio ambiente esquematizados na figura 5 .

\section{Figura 5 | Benefícios da implementação do Zoneamento Ecológico Econômico no Município do Rio de Janeiro}
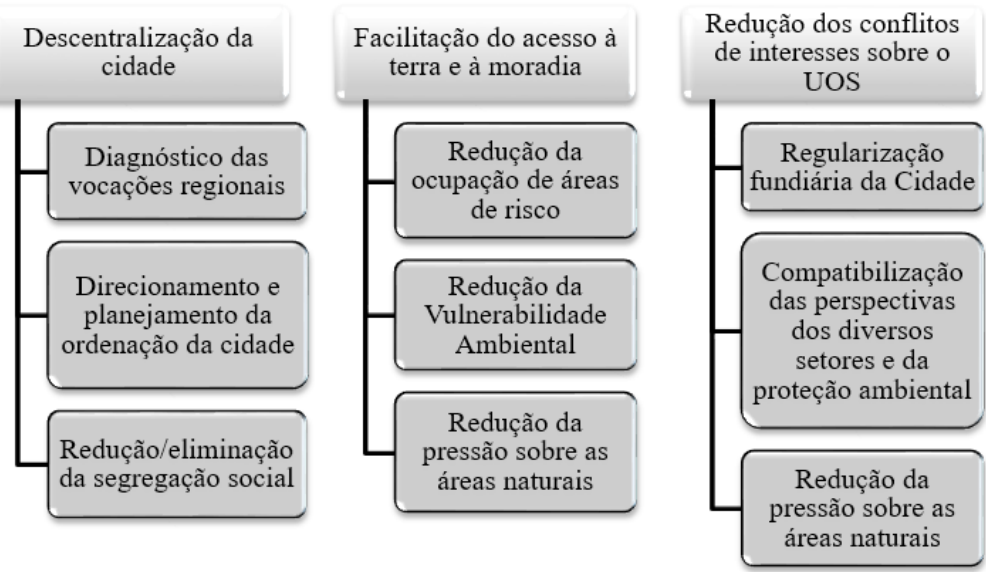

Integração de dados e informações e melhora na interlocução entre os diversos atores

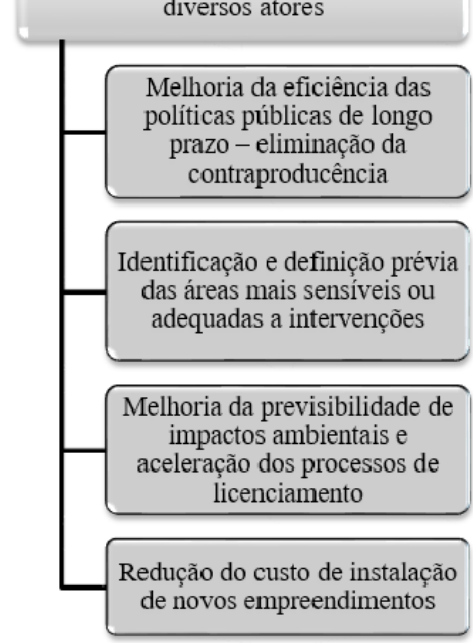

Planejamento integrado dos componentes ambientais com os econômicos e sociais

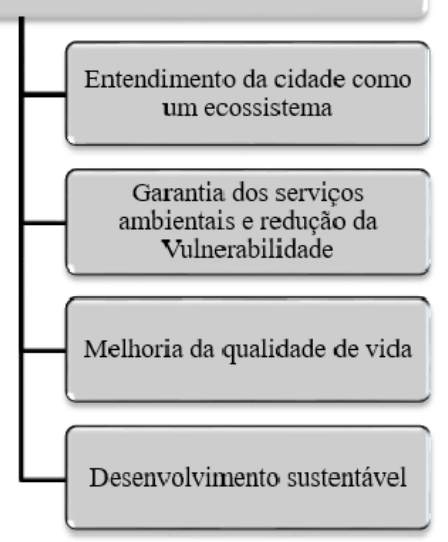


Desafios conceituais e práticos, abstratos e concretos, conjunturais e estruturais, podem ser elencados no processo de elaboração do instrumento zeE numa cidade complexa como o Rio de Janeiro.

Quanto aos desafios operacionais da implementação do ZEE, pode-se citar a dificuldade da formação de uma equipe multidisciplinar qualificada e a superação do desafio que envolve a cooperação e participação de universidades, centros de pesquisa e das estruturas de governo e seus técnicos, além da garantia da participação social a qual, na prática, ainda não tem sido realizada de maneira satisfatória, transparente e democrática em muitos outros processos os quais preveem esta participação. Neste sentido a fim de se evitar resultados contraproducentes é necessário que haja a priori um nivelamento de informaçôes entre estes agentes envolvidos e as instituiçóes governamentais envolvidas com o ordenamento territorial.

Outro desafio que surge é o da abordagem geográfica. Em uma possível proposta de zeE Local, os modelos de desenvolvimento (social, político, econômico, ambiental, regional/territorial) são essenciais para compreensão da dinâmica do espaço, dos seus conflitos e de uma proposta para minimização de impactos. No que diz respeito aos conflitos ambientais urbanos, estes devem ser entendidos ao longo do curso da história pelo qual atravessou a área em questão. Dessa forma, tomando como base a busca por uma noçáo de espaço urbano a ser utilizada no planejamento ambiental, deve-se entender que tal realidade espacial encontra a sua dinâmica e se transforma, não sendo absolutamente estática.

Entendendo o espaço e sua dinâmica ambiental, emerge a questão da negociação de conflitos ${ }^{4}$ que deve considerar a efetivação de diferentes estratégias orientadas por diversos atores que modelam o espaço geográfico. Portanto, no processo de negociação, cada grupo representa certa visão do problema (grupos ecologistas, agentes imobiliários, empresas, órgãos da administração pública, etc.). A negociação impóese, sob esta perceptiva, como condição para a tomada de decisão.

Mais um desafio é a integração do recorte, objeto do zoneamento, com outras escalas espaciais o que proporciona a inter-relação de diferentes olhares sobre a distribuição, extensão e abrangência geográfica a partir das perspectivas que surgem e atuam como filtros de apreensão da realidade. O zEE, por exemplo, ao partir da escala estadual ou regional para a local ou urbana, conforme orienta a Resoluçáo 4.297/02, deveria condicionar/orientar o planejamento urbano e não o inverso. Por outro lado, atores que atuam na escala local possuem estratégias e interesses diferentes daqueles que atuam na escala estadual/regional. Desta forma, o zeE é um instrumento de mediação de escalas espaciais, sendo este um desafio.

No quis diz respeito ao desafio de gerenciamento, tendo em vista o caráter dinâmico dos processos envolvidos na gestáo territorial, o zEE deve passar por constantes atualizaçôes, sendo assim um processo dinâmico de construção da informação, o que pode ser obstado pelo sistema burocrático hoje instalado na Administraçáo Pública municipal.

Repensar o desenvolvimento urbano é um caminho essencial para superar os desafios da sustentabilidade da ocupação e uso do solo na cidade como o Rio de Janeiro. 
Assim, como mencionado por Souza (1995), deve-se buscar uma mudança do modelo civilizatório envolvendo questôes ligadas à materialidade das tecnologias, à organização espacial e à gestão das tecnologias, da natureza e dos espaços.

Por fim, deve-se identificar e compreender todas as políticas setoriais previstas para a cidade, assim como os planos, programas e projetos relacionados para que não haja dissonância com as proposiçôes a serem feitas pelo zeE. Para que todos esses preceitos tenham sucesso, devemos parar de olhar o meio ambiente como uma peça isolada, a qual serve somente de obstáculo e limite ao crescimento urbano e sofre os impactos das atividades humanas realizadas em seu entorno. Deve-se pensar nos impactos múltiplos e cumulativos do uso e ocupação do solo sobre os recursos naturais e na via contrária, nos serviços ambientais prestados por estas a área urbana e a sociedade. Desta forma, a dimensão política do planejamento territorial do município deve ser redefinida de forma holística no sentido de se trabalhar o território como um todo, tanto na sua porção rural, quanto na área urbana propriamente dita.

\section{Referências bibliográficas}

Acselrad, H. (2004). As práticas espaciais e o campo dos conflitos espaciais.Em H. Acselrad(Org.), Conflitos Ambientais no Brasil (pp. 13-35). Rio de Janeiro: Relume Dumará.

Attanasio, G. M. C. (2005). Avaliação da obrigatoriedade do Zoneamento Ecológico Econômico, no contexto do licenciamento Ambiental. Dissertação de Mestrado. Escola de Engenharia de São Carlos, Universidade de São Paulo. São Carlos, sp, Brasil.

Batista, M. A. N. (2009). Candidatura do Rio de Janeiro a patrimônio mundial: Categoria paisagem cultural. 8 o Seminário Docomomo Brasil. Sumário de Trabalho. Rio de Janeiro, RJ, Brasil. 1-4 Set, 2009 Disponível em http://www.docomomo.org.br

Becker, B. K. \& Egler, C. A. G. (1997). Detalhamento da metodologia para execução do zoneamento ecológico-econômico pelos Estados da Amazônia Legal. Brasília: Ministério do Meio Ambiente (ммA). Em http://www.egler.com.br/pdf/Metodo_ZEE.pdf

Benatti, J. H. (2003). Aspectos legais e institucionais do Zoneamento Ecológico Econômico. Revista de Direito Ambiental, 8(29), 103-114.

Beser de Deus, L. A. (2013). Espaço e tempo como subsídios à construção de cenários de uso e cobertura da terra para o planejamento ambiental na Amazônia: O caso da Bacia do Rio Acre. Tese de Doutorado. Rio de Janeiro, Instituto Alberto Luiz Coimbra de PósGraduação e Pesquisa de Engenharia (COPPE), Universidade Federal do Rio de Janeiro (UFRJ).

Borsoi, A. M. (2007). Mineração e Conflito Ambiental: atores sociais e interesses em jogo na extração de granito no município de Nova Venécia - ES. Dissertação de Mestrado. Niterói, Universidade Federal Fluminense (UfF).

Brasil (2001). Lei Federal no 10.257, de 10 de julho de 2001. Coletânea de Legislação Ambiental $e$ Constituição Federal. RT - mini códigos. São Paulo: Editora Revista dos Tribunais, 2007. $6^{\circ}$ edição, atualizada até 16 jan. 2007. 
Conservation International. The Biodiversity Hotspots. Em http://www.conservation.org/How/ Pages/Hotspots.aspx

Coelho Netto, A. L. (2005). The urban-forest interface and water related natural disasters at Tijuca Massif: challenges for urban planning in a socio-environmental perspective. Revista do Departamento de Geografia, 16, 46-60. http://dx.doi.org/10.7154/ RDG.2005.0016.0005

Del Prette, M. E. \& Matteo, K. C. (2006). Origens e possibilidades do zoneamento ecológicoeconômico no Brasil. In Caderno de Referência: subsídios ao debate. Brasília, DF: Ministério do Meio Ambiente, Secretaria de Políticas para o Desenvolvimento Sustentável.. maio-junho. Disponível em http://www.mma.gov.br/sitio/index. php?ido $=$ conteudo. monta\&idEstrutura $=28 \&$ idConteudo $=8957 \&$ idMenu=9714

Ferreira, V. J. R. P. (2011). Avaliação do ZEE no Município do Rio de Janeiro como ferramenta para a Gestão Territorial Integrada e Desenvolvimento Sustentável. Mestrado de M.Sc. Programa Planejamento Energético. Rio de Janeiro, Instituto Alberto Luiz Coimbra de Pós-Graduaçáo e Pesquisa de Engenharia (COPpe), Universidade Federal do Rio de Janeiro (UfRJ), Programa de Planejamento Energético (PPE).

Fundação Estadual de Engenharia Do Meio Ambiente (FEEMA). (1997a). Qualidade de água da Baía de Guanabara. Rio de Janeiro, RJ: FEemA.

Fundação Estadual de Engenharia Do Meio Ambiente (feEma). (1997b). Rios da Baixada da Baía de Sepetiba - Diagnóstico da qualidade de águas e sedimentos. Rio de Janeiro, RJ: FEEMA.

Fundação Estadual de Engenharia do Meio Ambiente (FeEmA). (2006). Complexo Lagunar de Jacarepaguá - Diagnóstico de qualidade de água, periodo 2001 / 2005. Rio de Janeiro, RJ: FEEMA.

Galvão, M. C. C. (1992). Focos sobre a questão ambiental no Rio de Janeiro. In M. A. Abreu (Org.). Natureza e Sociedade no Rio de Janeiro. Rio de Janeiro: Biblioteca Carioca.

Healey, P. (1992). Planning through debate: The communicative turn in planning theory. Town PlanningReview, 63(2), 143-162.http_//dx.doi.10.3828/tpr.63.2.422x602303814821

Harvey, D. (2008). O direito à cidade. Traduzido do original em inglês "The right to the city", por Jair Pinheiro. Esta versão foi cotejada com a publicada na New Left Review, (53), 2008. Lutas Sociais. Disponível em http://www4.pucsp.br/neils/downloads/neilsrevista-29-port/david-harvey.pdf

Instituto Municipal de Urbanismo Pereira Passos (IPP). (2001). Moradia segregação, desigualdade e sustentabilidade. Coleção Estudos Cariocas. Armazém de Dados. Rio Estudos (13). Disponível em http://portalgeo.rio.rj.gov.br/_pcontrole/content/out/ content.asp?gcod $=109$

Instituto Municipal de Urbanismo Pereira Passos (IPP). (2009). Cidade do Rio de Janeiro - Uso do solo 2009., (Mapa No 3183). Mapoteca Rio de Janeiro, RJ. Disponível em http:// www.armazemdedados.rio.rj.gov.br/

Kikuchi M. Y. (2007). zeE e instrumentos de políticas públicas. In Caderno de Referência: subsidios ao debate. Brasília, DF: Ministério do Meio Ambiente, Secretaria de Políticas para o Desenvolvimento Sustentável. Disponível em http://www.mma.gov.br/sitio/index. php?ido=conteudo. monta\&idEstrutura $=28$ \&idConteudo $=8957 \&$ \&idMenu=9714 
Marques, V. J. \& Marques, S. S. (2007). Evolução da metodologia do zEe - aplicação de técnicas de cenários. In Caderno de Referência: subsídios ao debate. Brasília, DF: Ministério do Meio Ambiente, Secretaria de Políticas para o Desenvolvimento Sustentável. Disponível em http://www.mma.gov.br/sitio/index.php ?ido=conteudo. monta\&idEstrutura $=28 \&$ idConteudo $=8957 \&$ idMenu $=9714$

Ministério do Meio Ambiente (MMA). (2006a). Programa ZEE: diretrizes metodológicas para o zee do Território Nacional (3a ed.). Brasília, DF. MMA, Secretaria de Extrativismo e DesenvolvimentoRuralSustentável.Disponívelemhttp://www.mma.gov.br/sitio/index. php?ido=conteudo. monta\&idEstrutura $=28 \&$ idConteudo $=8219$ \&idMenu=8781

Ministério do Meio Ambiente (MMA). (2006b). Zoneamento ecológico econômico e proteção da biodiversidade. Seminário Zoneamento Ecológico Econômico e Biodiversidade. Caderno de Resumos. Brasília, DF. Disponível em http://www.mma.gov.br/sitio/index. php?ido $=$ conteudo monta\&idEstrutura $=28 \&$ idConteudo $=8959 \&$ idMenu=9716

Ministério do Meio Ambiente (MмA). (2011). Programa de Zoneamento Ecológico Econômico. Disponível em http://www.mma.gov.br

Oliveira, S. (2004). A releitura dos critérios de justiça na região dos Lagos do Rio de Janeiro. In H. Acselrad (Org.), Conflitos ambientais no Brasil (pp. 95-130). Rio de Janeiro, RJ: Relume Dumará.

Paula, F. S. \& Sales, M. C. L. (2007). O zoneamento ecológico-econômico como instrumento do planejamento ambiental. In II Congresso de Pesquisa e Inovação da Rede Norte Nordeste de Educação Tecnológica. João Pessoa, рв.

Pires do Rio, G. A. \& Galvão, M. C. C. (1996). Gestão ambiental: Apontamentos para uma reflexão. In Anuário do Instituto de Geociências, 16, 15-44 (Rio de Janeiro: Universidade Federal do Rio de Janeiro, UfRJ).

Rio de Janeiro (2011). Lei Complementar $n^{o} 111$, de $1^{o}$ de fevereiro de 2011. Dispóe sobre a Política Urbana e Ambiental do Município, institui o Plano Diretor de Desenvolvimento Urbano Sustentável do Município do Rio de Janeiro e dá outras providências. Disponível em http://www.portomaravilha.com.br/conteudo/ legislacao/LC111.2011.pdf

Scandurra, E. (1995). L'ambiente dell'uomo: verso il progetto della città sostenibile. Miláo: Etaslibri.

Santos, M., (1996). A natureza do espaço: técnica e tempo, razão e emoção. São Paulo: Hucitec.

Secretaria Municipal de Meio Ambiente (SMAC). (2000). Espécies ameaçadas de extinção no município do Rio de Janeiro: Fauna e Flora. Rio de Janeiro, RJ: Prefeitura da Cidade do Rio de Janeiro.

Secretaria Municipal de Meio Ambiente (sMAC). (2005). SMAC, 10 anos. Rio de Janeiro, RJ: Prefeitura da Cidade do Rio de Janeiro.

Secretaria Municipal de Meio Ambiente (smac). (2008). Macro-planejamento da Secretaria Municipal de Meio Ambiente. Documento fornecido diretamente pela SMAC.

Souza, M. L. (1995). A crescente fragmentação do tecido sócio-político-espacial das metrópoles do Rio de Janeiro e de São Paulo: Um desafio para a agenda do Desenvolvimento Urbano Sustentável. In Exclusão social, fragmentação do tecido sócio-político-espacial da cidade e 'ingovernabilidade urbana'. Ensaio a propósito do desafio de um 'desenvolvimento urbano sustentável' nas cidades brasileiras. $4^{\circ}$ Simpósio Nacional de Geografia Urbana. Fortaleza, outubro. 
Souza, M. L. (2000). O desafio metropolitano: um estudo sobre a problemática sócio-espacial nas metrópoles brasileiras. Rio de Janeiro, RJ: Bertrand Brasil.

Steinberg, M. \& Romero, M. B. (2000). Reflexôes preliminares sobre as dimensóes demográficas urbanas do zoneamento ecológico-econômico. In Encontro Nacional de Estudos Populacionais da ABEP, 12. Caxambu, MG. Anais: ABEP População e Meio Ambiente. Disponível em http://www.abep.org.br/usuario/ GerenciaNavegacao.php?caderno_ id $=085 \&$ nivel $=2$ 